Article

\title{
Visual Lateralization in the Cephalopod Mollusk Octopus vulgaris
}

\author{
Elisa Frasnelli ${ }^{1,2}, * \mathbb{C}$, Giovanna Ponte ${ }^{3}$, Giorgio Vallortigara ${ }^{2} \mathbb{C}$ and Graziano Fiorito ${ }^{3}$ \\ School of Life Sciences, University of Lincoln, Lincoln LN6 7DL, UK \\ 2 Center for Mind/Brain Sciences, University of Trento, Piazza della Manifattura 1, I-38068 Rovereto, Italy \\ 3 Department of Biology and Evolution of Marine Organisms, Stazione Zoologica Anton Dohrn, \\ I-80121 Napoli, Italy \\ * Correspondence: efrasnelli@lincoln.ac.uk; Tel.: +44-1522-835253
}

Received: 26 June 2019; Accepted: 20 August 2019; Published: 4 September 2019

\begin{abstract}
Behavioral asymmetries exhibited by the common octopus, Octopus vulgaris, a cephalopod mollusk, during predatory and exploratory responses were investigated. Animals were tested for eye preferences while attacking a natural (live crab) or an artificial (plastic ball) stimulus, and for side preferences while exploring a T-maze in the absence of any specific intra- or extra-maze cues. We found individual-level asymmetry in some animals when faced with either natural or artificial stimuli, but not when exploring the maze. Our findings suggest that visual lateralization in O. vulgaris is context-dependent.
\end{abstract}

Keywords: lateralization; asymmetry; brain asymmetry; behavioral asymmetry; vision; cephalopod; octopus; context-dependent; maze

\section{Introduction}

Functional specialization of the right and left sides of the brain is a characteristic feature of the vertebrate brain [1,2]. Asymmetries may appear as limb preferences (for review see [3]) or side biases in motor behaviors such as a turning preference (e.g., [4,5] or as eye preferences when inspecting visual stimuli (e.g., [6]). More recently, behavioral side-biases and underlying anatomical asymmetries have been found in invertebrates (review in [7]), suggesting that lateralization may be an essential feature of brains belonging to different taxa and distant in their evolutionary path.

Among the invertebrates, the common cuttlefish, Sepia officinalis (Cephalopoda, Sepiida, Sepiidae), and the common octopus, Octopus vulgaris (Cephalopoda, Octopoda, Octopodidae), together with all other representatives of the class Cephalopoda have their eyes placed laterally on the head [8-11]. This allows for about $360^{\circ}$ of the visual field, although it overlaps slightly in front of and behind the animal main antero-posterior axis (e.g., [12-14]). Once a stimulus comes into the visual field of the octopus, the animal typically orients its head and/or eyes in order to keep the prey/object in the visual field of both eyes (binocular vision) or of one eye only (monocular vision) [14]. Following the review by Borrelli [15] and on the basis of the knowledge available, the visual field of O. vulgaris is estimated to be $180^{\circ}$ per eye, although A. Packard (unpublished data) calculated it as being only $130-160^{\circ}$ (review in [15]). Considering that the mobility of the eyes is also compensated by the movements of the head and body [16,17], the center of the visual field of an octopus seems to be variable and depends on how the animal is 'focusing' on the target (i.e., with binocular or monocular vision).

During predatory behavior, animals adapt their visual field to the context and the situation. For example, a typical sequence of events occurs when S. officinalis recognizes and then predates upon a prey (e.g., $[18,19])$. Irrespective of the predatory-technique (stalk or swoop), three phases are recognized: (1) Attention toward the prey, accompanied by color and postural changes (for example 
exhibiting raised arms such as the vertical upward extension of the first pair of arms, often held separated in a V/S-shaped curve), and movements of the eyes and head; (2) Orientation while the animal turns by up to $180^{\circ}$ so that the prey comes in the front of the cuttlefish, and then swims toward or away from the prey establishing a proper attacking distance to be able to; and (3) Seizure by the ejection of the tentacles to catch the prey (see also $[16,20]$ ).

Behavioral asymmetries have been reported in predatory and anti-predatory responses, and agonistic and mating contexts in S. officinalis [21-23]. Marked lateralization has been found at a population-level using a T-maze [24]. Alves and coworkers found that three out 15 cuttlefish $(20 \%)$ showed a significant left preference, while a right preference was observed for the other eight individuals $(53 \%)$ in their choice in a T-maze task (no preference found in $27 \%$ of animals) [24]. Interestingly, cuttlefish showing a significant side-bias consistently chose the side of their initial choice.

Octopuses exhibit a more flexible predatory behavior $[14,16,25,26]$, and in some cases, orient themselves toward stimuli or attend the environment using a single eye at a time. Approaching a prey/target with a single-eye (monocularly) has been reported in many instances in $O$. vulgaris including hunting $[14,26]$. Byrne et al. $[27,28]$ observed the preferential use of one eye by an individual octopus when faced with stimuli presented in their visual field.

The ability of $O$. vulgaris to solve simple or complex mazes has been investigated in a series of studies (for review see [29], see also [30]). Exiting a maze has been considered a capability that an octopus can achieve either by chance or through organized processes of learning. Even when the exiting of a maze was random in initial trials [31,32], as experience proceeded, the time spent in solving the maze decreased [32,33], suggesting that some learning had taken place [34].

Nevertheless, side biases in octopuses tested in a simple T-maze in the absence of any visible and contingent reward have not being investigated (but see: [35,36]).

Here, we tested whether any behavioral asymmetry in O. vulgaris could be noted during predatory response such as attacking a prey or an artificial stimulus providing a reward, and in cases of exploration of a T-maze in the absence of any reward (Figure 1).

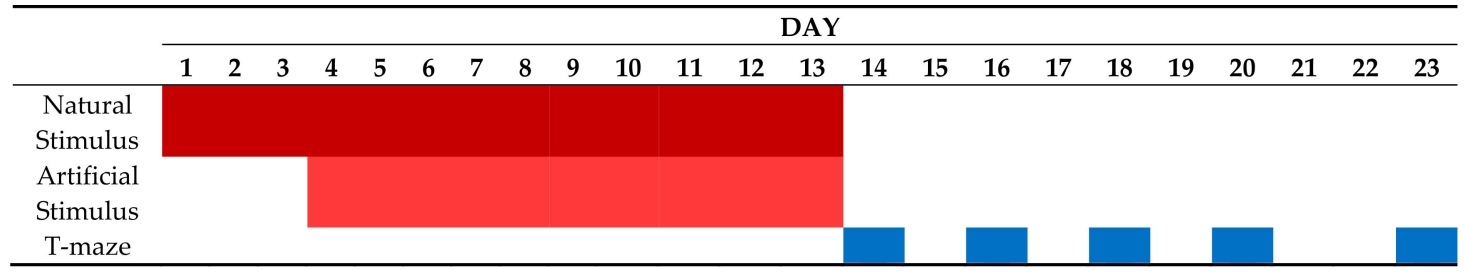

Figure 1. Schematic outline of the experimental plan and its timing.

\section{Materials and Methods}

\subsection{Animals}

Fifteen Octopus vulgaris, Cuvier 1797 ( 8 males, 6 females, and 1 immature animal; body mass range: 94-834 g; average: $350 \mathrm{~g}$ ), fished in the Bay of Napoli (Tyrrhenian Sea, Italy) between November 2012 and May 2013 were used in this study. In order to standardize the fishing procedures and possibly limit the inter-individual variability of the octopus, animals were collected by the same fisherman from the wild and the procedures for handling and care were standardized following Fiorito et al. [29] and Borrelli [15]. On arrival at the laboratory, each animal was numbered, sexed, weighed, and housed in an experimental tank with running seawater (for detail see: $[15,29]$ ). The experimental setting was designed to simulate natural conditions at a depth of 3-4 $\mathrm{m}$. The tanks were made of dark grey PVC (color components: Magenta $=10$, Black $=50$, Blue $=40$ ) except for the front side, which consisted of a transparent glass panel $(45 \times 35 \mathrm{~cm})$ to allow remote observation and video-recording. At about $1.5 \mathrm{~m}$ from the top of the tanks, lamps (Neodymlite, Oy Airam AB, Finland) were positioned and programmed to switch on and off automatically according to the seasonal and daily rhythm at the 
latitude of the Bay of Naples. The walls and the ceiling of the room was painted to match a dark color (color components: Magenta $=50$, Black $=70$, Blue $=100$ ) (for a description see also [15]). Animals were acclimatized to laboratory conditions before the start of the experiments, I other words, attacked a live crab readily within $20 \mathrm{~s}[15,25,26]$.

Some animals $(\mathrm{N}=7)$ were randomly accommodated in tanks with the den placed at the center of the posterior wall of the tank (Figure 2A), while other octopuses $(\mathrm{N}=8)$ were housed in tanks with the den positioned at the right corner of the posterior wall of the tank (Figure 2B).

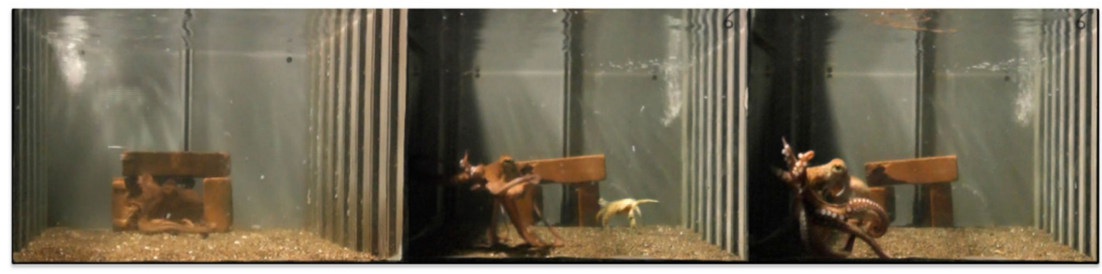

A

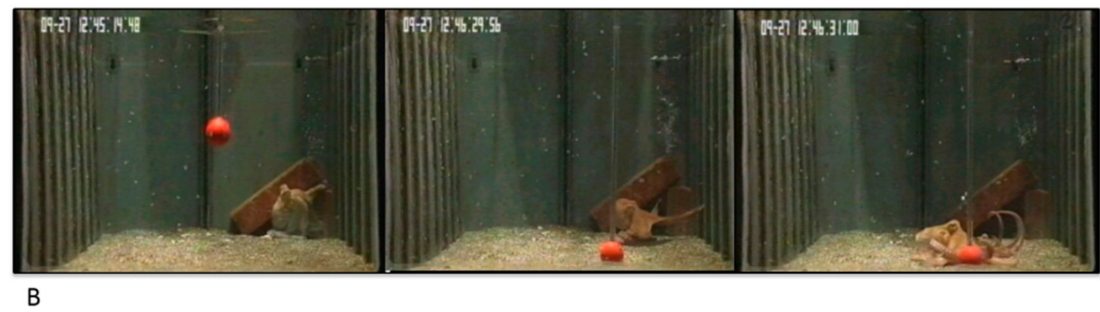

Figure 2. Typical behavioral responses of octopus to the natural (live crab; (A)) and artificial (plastic ball, (B) stimuli used in the study. Animals were accommodated in tanks where the den was positioned on the center of the posterior wall (e.g., (A) or on the right side (e.g., (B).

During the whole experiment, octopuses were fed a live crab (Carcinus maenas) every other day. Under these conditions, octopuses do not show a physiological or motivational decline in the propensity to attack [15,37].

\subsection{Scoring of Animals' Responses Toward the Target}

The type of attack performed by $O$. vulgaris toward visual stimuli is associated with the relative position/location of the animal with respect to the prey/stimulus. Thus, animals may either orient their head (and eyes) in order to keep the prey in the binocular visual field, or fixate the stimulus by monocular vision [14].

We thus classified the eye-use and the octopus' approaches to the target or choice in the maze as monocular 'left', monocular 'right', binocular (bino), and labelled the corresponding side that the animal utilized to approach the target as left, right, or no-preference.

\subsection{Experimental Procedure}

Each octopus was tested within 24 consecutive days to assess individual asymmetries in predatory responses (toward natural or artificial stimuli) and in a T-maze (Figure 1). Stimuli and the T-maze were presented to all animals in the same order. Octopuses were first tested for their predatory response (live $\mathrm{crab}$ ) for three days, and then continued to be exposed to live crab (morning) and artificial stimulus (afternoon; see below) for 10 consecutive days. These were followed by exploration of the T-maze (10 trials, arranged in five days in total, see Figures 1 and 3). 


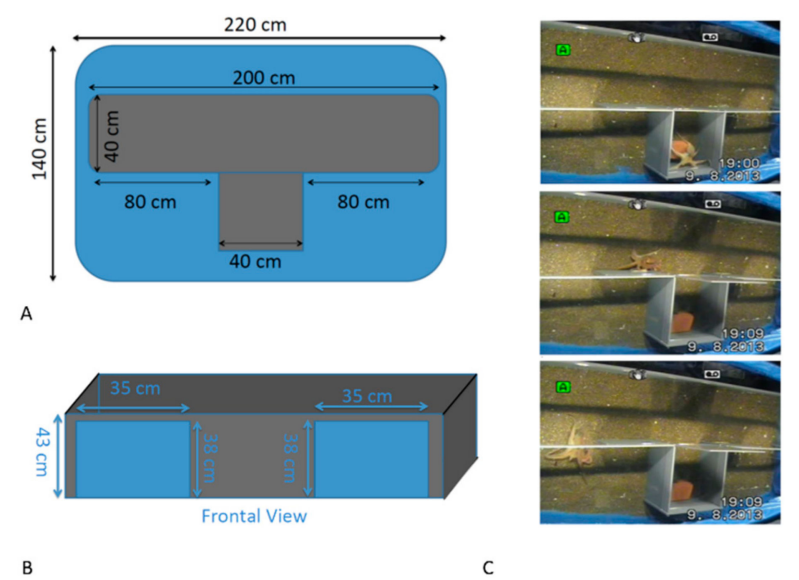

Figure 3. Schematic plan of the T-maze apparatus and holding tank that were utilized to test the possible preferences of O. vulgaris in exploring one side or the opposite. (A) Top view; (B) Frontal view. Sequential left turns performed in one trial by one of the octopuses tested are shown in $(\mathbf{C})$.

Predatory response was assessed in the octopus's home-tank, with animals accommodated either with side-biased or central dens (Figure 2). Octopuses were instead moved from their home-tank for the T-maze experiments (see below).

\subsubsection{Testing Asymmetry in Predatory Response: Natural Stimulus}

Octopuses were exposed to live prey to assess their readiness to attack $[15,37]$ in the morning. Tethered crabs (Carcinus maenas, Crustacea, Decapoda) were used as natural stimuli [37]. Once the prey landed on the bottom of the tank, it generally locomoted spontaneously; in the event the crab stayed still (freezing), the thread was gently pulled to solicit the prey to move. The crab was then promptly pulled out of the tank before the octopus could pounce on it (see also [37]). The tethered crab was presented to octopuses only when they remained calm in their dens (e.g., Figure 2A). Animals were exposed to the natural stimuli (Figure 2A) once a day (mornings) for a total of 13 trials (Figure 1). For each trial, we recorded the eye/side used by the octopus to first look outside its den before the crab was presented, and then to attack the crab. We also recorded the arms utilized to approach the crab (i.e., anterior and/or posterior right or left).

\subsubsection{Testing Asymmetry in Predatory Response: Artificial Stimulus}

After the first three days from the start of the experiment, octopuses were presented in the afternoon with a smooth plastic ball (red; Figures 1 and 2B). The ball (4 $\mathrm{cm}$ in diameter) was supplied with a pair of stainless steel small probes, protruding from its wall for $5 \mathrm{~mm}$ to deliver the reward and fixed at the extremity of a translucent nylon stick ( $80 \mathrm{~cm}$ in length); a cylinder handle, at the other end of the stick, allowed the experimenter to control the position and movement of the stimuli by hand. The ball was introduced and removed from the tank by hand, and landed at approximately at a distance of about $80 \mathrm{~cm}$ from the animal's resting position in the den (Figure 2B).

Each octopus was presented for three consecutive trials ( 2 min inter-trial interval) a day. The octopus received a reward for their attack to the ball (a small piece of anchovy; see [15] for detail) [38]. A total of 30 trials/animal were carried out for a total of 10 days (Figure 1).

As above, the eye-/side-utilized by animals for each trial was recorded before the presentation of the ball and once the animal grabbed the ball.

\subsubsection{Testing Asymmetry in Turning: The T-Maze}

A T-maze $(1 \times w \times$ h: $200 \times 80 \times 40 \mathrm{~cm}$, Figure 3$)$ made of matte grey PVC was used. A sliding door of the same material and color was positioned between the starting box and the central alley to 
create a "home" area to allow the octopus to stay quiet in the 'starting box' at the beginning of the experiment. A brick den was placed in the rear wall of the starting box.

The sliding door could be opened through a transparent nylon wire by the experimenters from a distance to prevent any interaction between the experimenter and the animal in the T-maze.

The T-maze had two exits on one side of each lateral arm, so that the animal had to turn in the same direction twice in order to exit the maze (Figure 3). The apparatus was placed in a large basin (dark blue in color) supplied with constant seawater flow and homogeneously lit by lights with a similar intensity to that of the holding tanks (for details see [15]). The water level was set at $35 \mathrm{~cm}$.

The bottom of the basin and of the T-maze was covered by a layer of sand [15], about $5 \mathrm{~mm}$ thick; [29]). A digital video camera (Panasonic HDC-SD80) positioned at about $2 \mathrm{~m}$ above the surface of the water video-recorded the entire apparatus and any movement of the animals during the experiment.

Octopuses were tested in five trials a day, every other day, for a total of 20 trials (see also Figure 1). The apparatus was rotated $180^{\circ}$ half way through the experiment so that each animal was tested for 10 trials with the apparatus in one position and for the remaining 10 trials with the apparatus oriented in the opposite way. Seven out of the 15 individuals started the experiment with the apparatus in the original orientation, while for the remaining eight octopuses, the T-maze was set in the $180^{\circ}$-rotated position.

Each octopus was left for at least $5 \mathrm{~min}$ in the starting box to acclimatize them to the new tank/condition, after which the sliding door was gently opened and the octopus had $10 \mathrm{~min}$ to complete the trial i.e., to exit the maze on one or other side of the T).

As soon as the octopus completed the maze, it was gently lifted out with a net and placed back in the start box for the following trial.

\subsection{Data Analysis}

For each octopus and each task, a laterality index was calculated as $L I=(L-R) /(L+R)$, where $L$ and $\mathrm{R}$ were the number of times the animals used the left or right eye/side in approaching the stimuli, or turned left- or rightward in the T-maze, respectively

Data collected throughout the experiments were tested for normality by using a Shapiro-Wilk's test. Pearson's correlation was carried out on LI to investigate possible relationships in performances in the three different tests. Repeated measures analyses of variance (ANOVA) were performed using tests (natural stimulus, artificial stimulus, and T-maze) and side (left and right) as within the subjects' effects. One-sample t-tests were used to assess population-level lateralization in each task. The binomial test (two-tailed) was applied to determine whether subjects had an eye preference by comparing the data for right and left eye use (or turns) at the individual level in each of the three tests.

All tests were two-tailed (unless otherwise stated) and the alpha was set at 0.05 .

\section{Results}

All animals readily approached the crab (morning session) during the first three days of the experiment and continued to show no significant deviances in their predatory response, as assessed by their latency to attacks (i.e., attacking the crab within $10 \mathrm{~s}$ on average; data not shown). However, a great variability among $O$. vulgaris individuals was observed (Table 1 and Figure 4 ) when asymmetries were considered: most animals did not show a consistent preference for a given side/orientation throughout the entire duration of the experiment. We found a significant positive correlation between $\mathrm{LI}$ (natural vs. artificial stimuli; $\mathrm{r}=0.678, p=0.005$; Figure 5), but not between the lateralization index resulting after the presentation of natural or artificial stimuli when compared with the performances in the T-maze (crab vs. T-maze: $\mathrm{r}=-0.20, p=0.945$, NS; ball vs. T-maze: $\mathrm{r}=-0.297, p=0.282$, NS). This suggests that $O$. vulgaris preferentially used the same eye when faced with natural and artificial stimuli. An ANOVA with task and side as within-subject effects revealed a significant effect of the task $\left(\mathrm{F}_{1,14}=3850, p<0.0001\right)$, but no significance for the effect of side $\left(\mathrm{F}_{1,14}=0.013, p=0.910\right)$. The interaction was not significant (side and task; $F_{1,14}=1080, p=0.353$ ) (Figure 4). 
Table 1. Individual performances by Octopus vulgaris expressed as the lateralization index (LI) toward natural and artificial stimuli and during exploration of an un-rewarded T-maze. Results of the binomial test (z-test approximation of the binomial test, expressed as the Z-score and relative $p$ ) are also presented. It is noteworthy to report that during the T-maze experiment, two O. vulgaris chose the right arm the same number times as the left arm (10 times), five individuals chose the left arm slightly more often than the right arm (11 left, nine right), two octopuses chose the right arm slightly more often than the left arm (11 right, nine left), while the remaining six individuals chose the right arm more often than the left one (three octopuses: 12 right, eight left; three octopuses: 13 right, seven left). The asterisks indicate significant difference: * for $p \leq 0.05$; ${ }^{* *}$ for $p \leq 0.01$; ${ }^{* *}$ for $p \leq 0.001$.

\begin{tabular}{cccccccccc}
\hline Animal \# & \multicolumn{3}{c}{ Natural Stimulus } & \multicolumn{3}{c}{ Artificial Stimulus } & \multicolumn{2}{c}{ T-Maze } \\
\hline & $\boldsymbol{L I}$ & Z-Score & $\boldsymbol{p}$ & $\boldsymbol{L I}$ & $\boldsymbol{Z}$-Score & $\boldsymbol{p}$ & $\boldsymbol{L I}$ & Z-score & $\boldsymbol{p}$ \\
\hline $\mathbf{1}$ & 0.50 & 1.44 & 0.150 & 0.00 & 0.00 & 1.000 & 0.10 & 0.22 & 0.820 \\
$\mathbf{2}$ & 0.17 & 0.29 & 0.770 & -0.20 & -0.91 & 0.360 & -0.30 & -1.12 & 0.260 \\
$\mathbf{3}$ & 0.27 & 0.60 & 0.550 & 0.27 & 1.28 & 0.200 & 0.10 & 0.22 & 0.820 \\
$\mathbf{4}$ & 0.83 & 2.60 & $0.010^{*}$ & 0.48 & 2.51 & $0.010^{*}$ & -0.20 & -0.67 & 0.500 \\
$\mathbf{5}$ & -0.33 & -0.87 & 0.390 & 0.35 & 1.80 & 0.070 & -0.30 & -1.12 & 0.260 \\
$\mathbf{6}$ & -0.33 & -0.87 & 0.390 & -0.55 & -2.87 & $0.003^{* *}$ & 0.10 & 0.22 & 0.820 \\
$\mathbf{7}$ & 0.33 & 0.87 & 0.390 & 0.80 & 4.20 & $>0.001^{* * *}$ & -0.20 & -0.67 & 0.500 \\
$\mathbf{8}$ & 0.08 & 0.00 & 1.000 & 0.27 & 1.28 & 0.200 & -0.10 & -0.22 & 0.820 \\
$\mathbf{9}$ & -0.17 & 0.29 & 0.770 & 0.29 & 1.32 & 0.180 & -0.10 & -0.22 & 0.820 \\
$\mathbf{1 0}$ & -0.67 & 2.02 & $0.040^{*}$ & -0.59 & -2.97 & $0.002^{* *}$ & 0.10 & 0.22 & 0.820 \\
$\mathbf{1 1}$ & 0.08 & 0.00 & 1.000 & 0.27 & 1.28 & 0.200 & 0.00 & 0.00 & 1.000 \\
$\mathbf{1 2}$ & -0.69 & 2.22 & $0.020^{*}$ & -0.47 & -2.37 & 0.020 & -0.30 & -1.12 & 0.260 \\
$\mathbf{1 3}$ & -0.38 & 1.11 & 0.270 & -0.87 & -4.56 & $>0.001$ & 0.00 & 0.00 & 1.000 \\
$\mathbf{1 4}$ & -0.23 & 0.55 & 0.580 & -0.27 & -1.28 & 0.200 & -0.20 & -0.67 & 0.500 \\
$\mathbf{1 5}$ & -0.17 & 0.29 & 0.770 & -0.27 & -1.28 & 0.200 & 0.10 & 0.22 & 0.820 \\
\hline
\end{tabular}

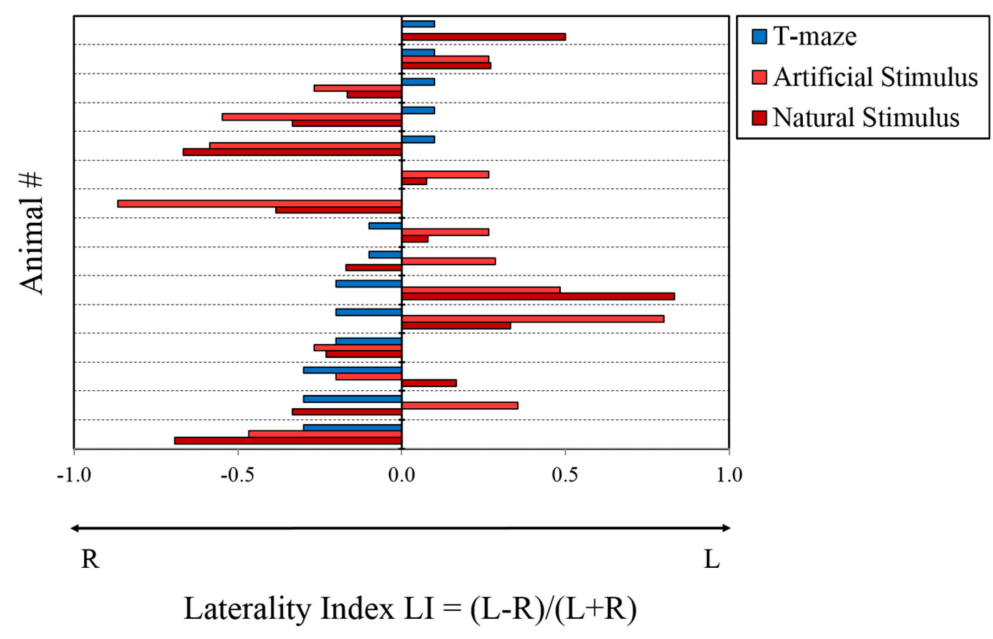

Figure 4. Laterality index of individual O. vulgaris $(\mathrm{N}=15)$ over the three tests: predatory response to a natural (natural stimulus; dark-red bars) and artificial (artificial stimulus; light-red bars) stimuli; and turning in a T-maze (T-maze; blue bars). 


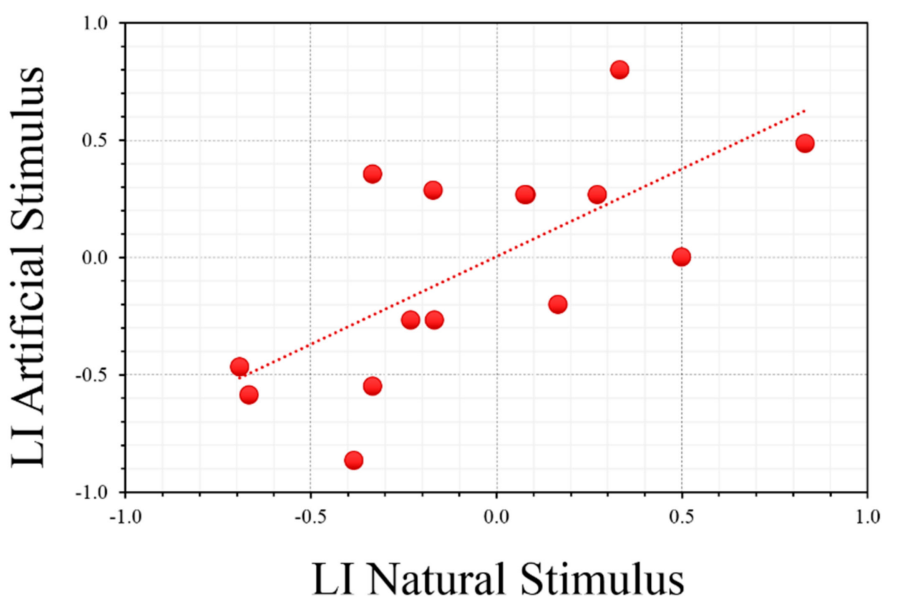

Figure 5. Correlation between laterality index of individual O. vulgaris $(\mathrm{N}=15)$ when presented to the natural (LI Natural Stimulus) or to the artificial (LI Artificial Stimulus) stimuli.

\subsection{Asymmetry in Predatory Response: Natural and Artificial Stimuli}

We found no evidence of lateralization at the population level when the eye/side preference in the octopus predatory response toward the crab $\left(\mathrm{t}_{(14)}=-0.43 ; p=0.673\right)$ or the artificial stimulus $\left.\mathrm{t}_{(14)}=-0.27 ; p=0.792\right)$ were considered. Binomial tests suggested that only three out of 15 individuals preferentially used one eye (the left one) in attacking the crab (Table 1), irrespective of the relative position of the den in the home-tank.

When presented with the artificial stimulus, seven octopuses (out of 15) preferentially used one eye (three animals the left eye; four octopuses the right eye). Interestingly, two of the three individuals that utilized the left eye/side when presented with the natural stimulus switched to the other one when exposed to the plastic ball and used the right eye/side.

The eye used to look outside the den seemed to strongly influence the eye/side employed during the attack. We found that the eye used by octopuses to look at their surroundings before the attack strongly correlated with the eye used to attack the live crab $(\mathrm{r}=0.99 ; p<0.001)$ and this also held true when the animals were presented with artificial stimuli $(\mathrm{r}=0.99 ; p<0.001)$.

In order to test whether the position of the den inside the tank was a factor influencing lateralization, a two-way ANOVA (with home position as the factor) was performed, but did not reveal any significant effect in the eye used before $\left(\mathrm{F}_{1,13}=0.02, p=0.904\right)$, or during the attack on the live crab $\left(\mathrm{F}_{1,13}=0.01\right.$, $p=0.935)$, and in the eye used before $\left(\mathrm{F}_{1,13}=2.04, p=0.177\right)$ or during the attack on the plastic ball $\left(\mathrm{F}_{1,13}=2.14, p=0.167\right)$. However, $O$. vulgaris that had their home position on the right were more consistent in the choice of their preferred eye, both when presented with the natural and artificial stimuli, than octopuses with the den in the central location. We also found a positive correlation between the eye used to attack the crab and the ball in animals with the den placed in the right side of the tank $(r=0.72, p=0.044)$, but not in animals with the den placed in the center of the tank $(r=0.73$, $p=0.065)$.

\subsection{T-Maze}

Ten out of 15 octopuses (binomial test, two-tailed $p=0.302$ ) turned rightward in the first trial, independently of the relative orientation of the apparatus. However, when tested over the 20 trials, no population-level bias to turn right- or leftward was found apart from a trend $\left(\mathrm{t}_{14}=-1.92, p=0.075\right.$; Figure 4).

The relative position of the den in the home-tank did not affect the animal responses. Octopuses with a den in the center of the tank $\left(\mathrm{t}_{6}=-1.73, p=0.134\right)$ and those housed in tanks with the den positioned on one side $\left(t_{7}=-1.00, p=0.351\right)$ did not show any side-preference at the population-level. 
At the individual-level, no animals showed a consistent preference to use one eye/side over the other (see Table 1).

\section{Discussion}

We found no significant population-level asymmetry in O. vulgaris in any of the three tests, apart from a tendency to turn rightward when exploring the T-maze. This will clearly require further testing with a larger sample.

Instead, our results revealed a clear asymmetry in some individuals when tested for their predatory response: three individuals with a clear bias when faced with a natural stimulus and seven when faced with the artificial one (out of the $15 \mathrm{O}$. vulgaris tested). We did not observe any marked preference for either the left or right side when animals explored the T-maze.

The predatory response of the octopuses was tested in this study using a live crab and a plastic ball. We expected that while performing an attack/approach during the elicited predatory behavior, some animals may reveal a preference for the use of left or the right eye/side. We also expected a correlation between the side/eye use when exposed to the two stimuli (i.e., natural or artificial; see $[39,40]$ for evidence in vertebrates of different lateralization for animated and non-animated stimuli).

We also tested whether the $O$. vulgaris who revealed a preferential use of a given eye/side during predatory response might consistently show a turning bias in the same direction while exploring a T-maze, possibly suggesting that the same eye/side may be used in both exploratory and predatory behaviors. Finally, we also explored whether the relative position of the den in the tank (i.e., at the right corner or at the center of one of the posterior walls of the tank) had an effect on the eye/side utilized by animals.

When presented with a stimulus, the octopuses moved out from their den toward the stimulus using a 'dominant' eye. We found that individuals showed asymmetry for either the left or right side/eye, similar to what has been reported by previous studies in different experiments (as reported by Byrne et al. in $O$. vulgaris: five left/three right, $N=8$ [27]; 13 left/10 right, $N=25$ [28]). Byrne and coworkers did not report the starting position of the animal when inside the den prior the presentation of the stimulus, and the relative position of the den inside the tank $[27,28]$. Consequently, it is difficult to determine whether the eye used by the octopuses to approach the stimulus was influenced by the starting position of the animal in the den.

The lack of asymmetry at the level of population when exploring the T-maze may be related to the absence of specific cues at the end of the T-maze' arms, which may affect the motivation of the octopus and thus their possible side-preference (e.g., [41,42]). Octopuses seem to differ from cuttlefish in this regard [24], as S. officinalis showed a population-level bias even when only shelters were provided at the end of each arm of the maze.

However, theoretical models on the evolution of lateralization $[43,44]$ suggest that lateralization at a population-level arises as a consequence of selective social pressures that push individuals to align their asymmetry within the population in order to coordinate better in specific tasks. This is the case for social interactions in solitary insects such as red mason bees [45]. As a consequence, the lack of asymmetry in the maze we observed may be explained as a lack of social coordination needed in this species whilst exploring new environments. This contrasts with what was observed in S. officinalis who are forced into a gregarious life-style under captive experimental rearing conditions [24,46,47].

At both the individual- and population-level, lateralization may be present in the same species depending on the type of task, as suggested by Frasnelli and Vallortigara [48]. Indeed, in tasks that require coordination among individuals, it is more beneficial to the majority of the population to be lateralized in the same direction, but in other contexts, it may be more advantageous to be lateralized at the individual-level. 
Author Contributions: All authors conceived the study. E.F. ran the experiments with the constant help and support of G.F. and G.P.; E.F. analyzed the data with inputs from G.F. All authors wrote the paper.

Funding: This research was funded by RITMARE Flagship Project (MIUR and SZN) supporting G.P. and G.F.; G.P. is currently supported through a SZN-BEOM Department fellowship.

Acknowledgments: We are grateful to Marinella Salemme (Association for Cephalopod Research 'CephRes', Italy) and Elizabeth Leimkuhler (Harvard University, USA during her internship at the G.F. Laboratory at SZN, Italy) for the care of the animals and for assistance in conducting the experiments with the live animals.

Conflicts of Interest: The authors declare no conflicts of interest.

\section{References}

1. Rogers, L.J.; Vallortigara, G.; Andrew, R.J. Divided Brains: The Biology and Behaviour of Brain Asymmetries; Cambridge University Press: Cambridge, UK, 2013.

2. Rogers, L.J. Asymmetry of brain and behavior in animals: Its development, function, and human relevance. Genesis 2014, 52, 555-571. [CrossRef]

3. Versace, E.; Vallortigara, G. Forelimb preferences in human beings and other species: Multiple models for testing hypotheses on lateralization. Front. Psychol. 2015, 6, 233. [CrossRef] [PubMed]

4. Dadda, M.; Koolhaas, W.H.; Domenici, P. Behavioural asymmetry affects escape performance in a teleost fish. Biol. Lett. 2010, 6, 414-417. [CrossRef] [PubMed]

5. Stancher, G.; Sovrano, V.A.; Vallortigara, G. Chapter 2-Motor asymmetries in fishes, amphibians, and reptiles. In Progress in Brain Research; Forrester, G.S., Hopkins, W.D., Hudry, K., Lindell, A., Eds.; Elsevier: Amsterdam, The Netherlands, 2018; Volume 238, pp. 33-56.

6. Tommasi, L.; Andrew, R.; Vallortigara, G. Eye use in search is determined by the nature of task in the domestic chick (Gallus gallus). Behav. Brain Res. 2000, 112, 119-126. [CrossRef]

7. Frasnelli, E.; Vallortigara, G.; Rogers, L.J. Left-right asymmetries of behaviour and nervous system in invertebrates. Neurosci. Biobehav. Rev. 2012, 36, 1273-1291. [CrossRef]

8. Jereb, P.; Roper, C. Chambered Nautiluses and Sepioids (Nautilidae, Sepiidae, Sepiolidae, Sepiadariidae, Idiosepiidae and Spirulidae); FAO: Rome, Italy, 2005; Volume 1, p. 262.

9. Jereb, P.; Roper, C. Cephalopods of the World. An Annotated and Illustrated Catalogue of Species Known to Date. Volume 2. Myopsid and Oegopsid Squids; FAO: Rome, Italy, 2010; p. 605.

10. Jereb, P.; Roper, C.; Norman, M.; Finn, J. Cephalopods of the World. An Annotated and Illustrated Catalogue of Species Known to Date. Volume 3. Octopods and Vampire Squids; FAO: Rome, Italy, 2016; p. 370.

11. Guerra, Á. Functional Anatomy: Macroscopic Anatomy and Post-mortem Examination. In Handbook of Pathogens and Diseases in Cephalopods; Springer: Berlin, Germany, 2019; pp. 11-38.

12. Watanuki, N.; Kawamura, G.; Kaneuchi, S.; Iwashita, T. Role of vision in behavior, visual field, and visual acuity of cuttlefish Sepia esculenta. Fish. Sci. 2000, 66, 417-423. [CrossRef]

13. Williamson, R. A sensory basis for orientation in cephalopods. J. Mar. Biol. Assoc. U.K. 1995, 75, 83-92. [CrossRef]

14. Packard, A. The behaviour of Octopus vulgaris. Bulletin de l'Institut océanographique 1963, Numéro spécial 1D. 35-49.

15. Borrelli, L. Testing the Contribution of Relative Brain Size and Learning Capabilities on the Evolution of Octopus Vulgaris and Other Cephalopods. Ph.D. Thesis, Stazione Zoologica Anton Dohrn, Italy \& Open University, Rome, Italy, 2007.

16. Borrelli, L.; Gherardi, F.; Fiorito, G. A Catalogue of Body Patterning in Cephalopoda; Stazione Zoologica A. Dohrn; Firenze University Press: Napoli, Italy, 2006.

17. Hanlon, R.T.; Messenger, J.B. Cephalopod Behaviour, 2nd ed.; Cambridge University Press: Cambridge, UK, 2018.

18. Duval, P.; Chichery, M.-P.; Chichery, R. Prey capture by the cuttlefish (Sepia officinalis L): An experimental study of two strategies. Behav. Process. 1984, 9, 13-21. [CrossRef]

19. Messenger, J.B. Learning in the cuttlefish, Sepia. Anim. Behav. 1973, 21, 801-826. [CrossRef]

20. Messenger, J.B. The visual attack of the cuttlefish, Sepia officinalis. Anim. Behav. 1968, 16, 342-357. [CrossRef] 
21. Schnell, A.K.; Jozet-Alves, C.; Hall, K.C.; Radday, L.; Hanlon, R.T. Fighting and mating success in giant Australian cuttlefish is influenced by behavioural lateralization. Proc. R. Soc. B 2019, 286, 20182507. [CrossRef] [PubMed]

22. Schnell, A.K.; Hanlon, R.T.; Benkada, A.; Jozet-Alves, C. Lateralization of eye use in cuttlefish: Opposite direction for anti-predatory and predatory behaviors. Front. Physiol. 2016, 7, 620. [CrossRef] [PubMed]

23. Schnell, A.K.; Bellanger, C.; Vallortigara, G.; Jozet-Alves, C. Visual asymmetries in cuttlefish during brightness matching for camouflage. Curr. Biol. 2018, 28, R925-R926. [CrossRef] [PubMed]

24. Alves, C.; Chichery, R.; Boal, J.G.; Dickel, L. Orientation in the cuttlefish Sepia officinalis: Response versus place learning. Anim. Cogn. 2007, 10, 29-36. [CrossRef] [PubMed]

25. Maldonado, H. The positive learning process in Octopus vulgaris. Z. Vgl. Physiol. 1963, 47, 191-214. [CrossRef]

26. Maldonado, H. The visual attack learning system in Octopus vulgaris. J. Theor. Biol. 1963, 5, 470-488. [CrossRef]

27. Byrne, R.A.; Kuba, M.; Griebel, U. Lateral asymmetry of eye use in Octopus vulgaris. Anim. Behav. 2002, 64, 461-468. [CrossRef]

28. Byrne, R.A.; Kuba, M.J.; Meisel, D.V. Lateralized eye use in Octopus vulgaris shows antisymmetrical distribution. Anim. Behav. 2004, 68, 1107-1114. [CrossRef]

29. Fiorito, G.; von Planta, C.; Scotto, P. Problem solving ability of Octopus vulgaris Lamarck (Mollusca, Cephalopoda). Behav. Neural Biol. 1990, 53, 217-230. [CrossRef]

30. Moriyama, T.; Gunji, Y.P. Autonomous learning in maze solution by Octopus. Ethology 1997, 103, 499-513. [CrossRef]

31. Bierens de Haan, J.A. Versuche ueber den Farbensinn und das psychische Leben von Octopus vulgaris. Z. Vgl. Physiol. 1926, 4, 766-796. [CrossRef]

32. Boycott, B.B. Learning in Octopus vulgaris and other cephalopods. Pubbl. Staz. Zool. Napoli. 1954, 25, 67-93.

33. Buytendijk, F.J.J. Das Verhalten von Octopus nach teilweiser zerstörung des "Gehims". Arch. Neert. Physiol. 1933, 18, 24-70.

34. Wells, M.J. Learning and movement in octopuses. Anim. Behav 1965, (Suppl. 1), 115-128.

35. Hvorecny, L.M.; Grudowski, J.L.; Blakeslee, C.J.; Simmons, T.L.; Roy, P.R.; Brooks, J.A.; Hanner, R.M.; Beigel, M.E.; Karson, M.A.; Nichols, R.H.; et al. Octopuses (Octopus bimaculoides) and cuttlefishes (Sepia pharaonis, S. officinalis) can conditionally discriminate. Anim. Cogn. 2007, 10, 449-459. [CrossRef] [PubMed]

36. Boal, J.G.; Dunham, A.W.; Williams, K.T.; Hanlon, R.T. Experimental evidence for spatial learning in octopuses (Octopus bimaculoides). J. Comp. Psychol. 2000, 114, 246. [CrossRef]

37. Amodio, P.; Andrews, P.; Salemme, M.; Ponte, G.; Fiorito, G. The Use of Artificial Crabs for Testing Predatory Behavior and Health in the Octopus. Altex-Altern. Anim. Exp. 2014, 31, 494-499.

38. Fiorito, G.; Scotto, P. Observational Learning in Octopus vulgaris. Science 1992, 256, 545-547. [CrossRef]

39. Forrester, G.S.; Leavens, D.A.; Quaresmini, C.; Vallortigara, G. Target animacy influences gorilla handedness. Anim. Cogn. 2011, 14, 903-907. [CrossRef]

40. Forrester, G.S.; Quaresmini, C.; Leavens, D.A.; Spiezio, C.; Vallortigara, G. Target animacy influences chimpanzee handedness. Anim. Cogn. 2012, 15, 1121-1127. [CrossRef] [PubMed]

41. Bisazza, A.; Facchin, L.; Pignatti, R.; Vallortigara, G. Lateralization of detour behaviour in poeciliid fish: The effect of species, gender and sexual motivation. Behav. Brain Res. 1998, 91, 157-164. [CrossRef]

42. Bisazza, A.; Pignatti, R.; Vallortigara, G. Detour tests reveal task-and stimulus-specific behavioural lateralization in mosquitofish (Gambusia holbrooki). Behav. Brain Res. 1997, 89, 237-242. [CrossRef]

43. Ghirlanda, S.; Vallortigara, G. The evolution of brain lateralization: A game-theoretical analysis of population structure. Proc. R. Soc. Lond. Ser. B Biol. Sci. 2004, 271, 853-857. [CrossRef] [PubMed]

44. Ghirlanda, S.; Frasnelli, E.; Vallortigara, G. Intraspecific competition and coordination in the evolution of lateralization. Philos. Trans. R. Soc. B Biol. Sci. 2009, 364, 861-866. [CrossRef] [PubMed]

45. Rogers, L.; Frasnelli, E.; Versace, E. Lateralized antennal control of aggression and sex differences in red mason bees, Osmia bicornis. Sci. Rep. 2016, 6, 29411. [CrossRef]

46. Jozet-Alves, C.; Viblanc, V.A.; Romagny, S.; Dacher, M.; Healy, S.D.; Dickel, L. Visual lateralization is task and age dependent in cuttlefish, Sepia officinalis. Anim. Behav. 2012, 83, 1313-1318. [CrossRef] 
47. Jozet-Alves, C.; Romagny, S.; Bellanger, C.; Dickel, L. Cerebral correlates of visual lateralization in Sepia. Behav. Brain Res. 2012, 234, 20-25. [CrossRef]

48. Frasnelli, E.; Vallortigara, G. Individual-level and population-level lateralization: Two sides of the same coin. Symmetry 2018, 10, 739. [CrossRef]

(C) 2019 by the authors. Licensee MDPI, Basel, Switzerland. This article is an open access article distributed under the terms and conditions of the Creative Commons Attribution (CC BY) license (http://creativecommons.org/licenses/by/4.0/). 